\title{
An Updated Systematic Review With Meta-Analysis Of Randomized Trials On Topical Cyclosporin A For Dry-Eye Disease
}

This article was published in the following Dove Press journal: Drug Design, Development and Therapy

\author{
Hsin-I Tuan ${ }^{1,2}$ \\ Sheng-Chu Chi iD ${ }^{3,4}$ \\ Yi-No Kang (iD ${ }^{5,6}$ \\ 'Department of Medicine, Taipei \\ Veterans General Hospital, Taipei, \\ Taiwan; ${ }^{2}$ School of Medicine, College of \\ Medicine, Taipei Medical University, \\ Taipei, Taiwan; ${ }^{3}$ Department of \\ Ophthalmology, Taipei Veterans General \\ Hospital, Taipei, Taiwan; ${ }^{4}$ Department of \\ Education, Linkou Chang Gung Memorial \\ Hospital, New Taipei City, Taiwan; \\ ${ }^{5}$ Center for Evidence-Based Medicine, \\ Department of Education, Taipei Medical \\ University Hospital, Taipei, Taiwan; \\ ${ }^{6}$ Cochrane Taiwan, Taipei Medical \\ University, Taipei, Taiwan
}

\section{Video abstract}

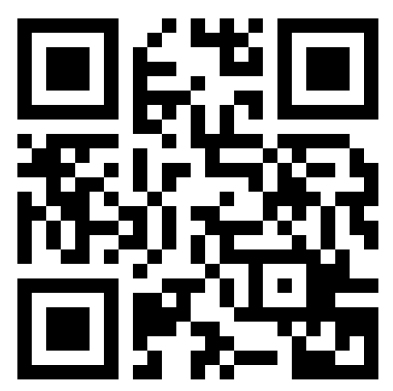

Point your SmartPhone at the code above. If you have a $O R$ code reader the video abstract will appear. Or use: https://youtu.be/IX9_2xdnXqc

Correspondence: Yi-No Kang Center for Evidence-Based Medicine, Department of Education, Taipei Medical University Hospital, 252 Wuxing Street,

Xinyi District, Taipei I10, Taiwan,

Tel +886227372181 Ext 3759

Fax +886266389622

Email academicnono@gmail.com
Background/Aims: To evaluate the effects of topical cyclosporin A (CsA) and artificial tears (ATs) for treating patients with dry-eye disease (DED).

Methods: On January 25, 2019, five electronic databases and reference lists were searched for randomized clinical trials (RCTs) comparing CsA with ATs among patients with DED. The search strategy had no restriction on language or time. Two authors extracted surgery, mean age, anesthesia for Schirmer's test, tear-breakup time, Schirmer's test score, fluorescein-staining score, ocular surface-disease index, and adverse events. Mean differences (MDs) were calculated for continuous outcomes and Peto ORs for dichotomous data with zero cells. Results were analyzed with $95 \%$ CIs in a random-effect model.

Results: Eleven RCTs recruiting 1,085 cases with DED were included. Pooled results showed that CsA had better tear-breakup time (MD 0.94, 95\% CI 0.08-1.80), fluoresceinstaining score (standardized MD $-0.72,95 \%$ CI -1.28 to -0.16 ), and ocular surface-disease index (MD $-4.75,95 \%$ CI -6.31 to -3.18 ) when compared to ATs. Although CsA had more adverse events than ATs (Peto OR 7.70, 95\% CI 3.17-18.68), no serious adverse events were reported.

Conclusion: Overall, CsA is an effective option for treating patients with DED, yet our evidence indicated decreasing effects when CsA was combined with ATs. CsA may be worth suggesting to relatively older patients with DED. We anticipate further RCTs to explore the effects of treatment duration, optimal dosage, and efficacy of CsA in different DED etiology. Keywords: dry eye, cyclosporin A, meta-analysis

\section{Introduction}

Dry eye disease (DED; keratoconjunctivitis sicca), is one of the most common ophthalmological diseases, affecting $7 \%-33 \%$ of older population. ${ }^{1-3}$ This multifactorial disease is commonly observed among females, and its prevalence increases with age. ${ }^{4,5}$ DED causes many symptoms, including blurred vision, burning sensation, and photophobia. These symptoms impair daily life and lead to loss in productivity. ${ }^{6}$ Therefore, appropriate management of DED is now an important issue around the world.

Multiple pathophysiology mechanisms induce DED, eg, dysfunction in lacrimal glands, inflammation of the ocular surface, and interconnecting neural pathways. These various mechanisms cause unstable tear film, hyperosmolar tears, and a damaged ocular surface, ${ }^{7}$ resulting in a vicious cycle and making symptoms progress. ${ }^{8} \mathrm{~T}$ cell-related inflammatory processes play an important 
role in DED. Once an inflammatory cascade presents, $\mathrm{T}$ cells abort apoptosis of the epithelium on the ocular surface, increase cytokines secretion, and recruit more $\mathrm{T}$ cells to the ocular surface, remaining for about 110 days. ${ }^{9}$ Therefore, immunomodulators are considered a promising treatment for DED.

The Tear Film and Ocular Surface Society International Dry Eye Workshop suggested DED management according to DED stage. Topical immunomodulatory agents, such as steroids and nonsteroid drugs, are recommended in stage two DED. ${ }^{10}$ While topical steroids are beneficial in DED, they also result in various complications, including cataracts and glaucoma. ${ }^{11}$ To avoid these compilations, clinical trials have investigated nonsteroid drugs, and a popular treatment in those trials has been cyclosporine A (CsA). A common immunomodulator, CsA decreases the number of activated $T$ cells and the expression of inflammatory markers in the conjunctiva of patients with DED. ${ }^{12,13}$ It not only regulates inflammation but also prevents apoptosis in epithelial cells of conjunctiva. ${ }^{12,14}$ CsA was approved by the US Food and Drug Administration for treating patients with moderatesevere DED in 2013. ${ }^{15}$

Although synthesized evidence has reported efficacy of CsA in the past decade, ${ }^{16-19}$ results have been highly heterogeneous. $^{18,19}$ For instance, the pooled results of ocular surface-disease index (OSDI; $I^{2}=82 \%$ ), tearbreakup time (TBUT; $I^{2}=96 \%$ ), and Schirmer's test $\left(I^{2}=92 \%\right)$ in the last synthesized evidence in 2015 reflected vary high heterogeneity, which may have been due to age, treatment duration, and drug formulation. Our study aimed to figure out the real effect of CsA by gathering the newest evidence on this topic and exploring sources of heterogeneity.

\section{Methods}

Our team members are medical doctors in a department of ophthalmology and an experienced researcher in systematic reviews with meta-analysis. ${ }^{20-23}$ We completed the evidence selection, quality assessment, and quantitative synthesis according to the PRISMA guidelines. ${ }^{24}$ The study protocol was registered on PROSPERO (CRD42019117429): https://www.crd.york.ac.uk/ $\underline{\text { PROSPERO/display record.php?RecordID }=117429}$.

\section{Study Selection}

To examine the effects of CsA and artificial tears (ATs) on DED, we defined eligible criteria for evidence selection beforehand. Inclusion criteria were randomized clinical trials (RCT), patients with DED, and comparing CsA to ATs. Two authors (HIT and SCC) selected evidence independently. The other author (YNK) made final judgments through discussion for any disagreement on evidence selection.

\section{Data Sources And Search Strategy}

We searched the Cochrane library (CENTRAL), Embase, PubMed, Scopus, and Web of Science for RCTs comparing effects of CsA and ATs among patients with DED. Our primary search strategy was built in PubMed using natural language, medical subject headings (MeSH in PubMed and Emtree in Embase), and abbreviations of relevant terms of CsA and DED. We did not put restrictions on language or publication date. Then, we adapted the search strategy to the other databases before January 25, 2019 (online supplementary file 1).

\section{Quality Assessment And Data Extraction}

Two authors (HIT and SCC) individually reviewed the included RCTs by using the Cochrane risk-of-bias tool. This tool consists of seven items for evaluating methodological bias. These authors also extracted relevant information about location, sample size, mean age, sex, treatment, treatment duration, anesthesia for Schirmer's test, and outcome data. Outcome data comprised TBUT, Schirmer's test, fluorescence-staining test, and OSDI score. Any disagreement on data definition was discussed by all authors.

\section{Data Synthesis And Analysis}

This study used pairwise meta-analyses for quantitative synthesis. Means and SDs were extracted for outcomes of TBUT, Schirmer's test, fluorescence-staining test, and OSDI score. Weighted mean differences (WMDs) with 95\% CIs were calculated for outcomes with continuous data. Numbers of events were extracted for side-effect outcomes. Peto ORs with 95\% CIs were calculated for the outcomes with binary data when any zero-cell value was reported. We pooled data in a random-effect model for all outcomes. When $P<0.05$, we judged the outcome statistically significant.

Because some potential factors may affect pooled results, we used subgroup analysis and metaregression for clarifying effects from treatment duration, combination therapy, mean age, and type of Schirmer's test in trials. Moreover, we examined heterogeneity and small-study 
effects for pooled results. We further conducted sensitivity analyses for those highly heterogeneous results. To detect small-study effects, we drew funnel plots with Egger's test. When the Egger's regression intercept reached statistical significance, we judged that this a biased finding.

\section{Results}

We identified 642 references from five electronic databases. After duplicates and irrelevant references had been removed, we retrieved 23 full texts for review. Lastly, the eligible 12 references from eleven RCTs were included in this study for qualitative and quantitative synthesis. ${ }^{25-36}$ The flow diagram of evidence selection is shown in Figure 1.

\section{Characteristics And Quality Of Included Studies}

The eleven eligible RCTs recruited 1,085 patients with DED from the US ${ }^{28,30,32-34}$ and Asia during 2006-2016. ${ }^{25-27,29,35,36}$ Available information showed that the mean age in each RCT was $39.45-73$ years. A total of $164(29.13 \%)$ males were included in the RCTs. Treatment duration was 2-12 months (Table 1). Overall, the quality of the included RCTs is shown in online supplementary file 2. Unfortunately, these trials provided patients different prescriptions with diverse dosage and frequency. Furthermore, some of those trials also allowed patients in the CsA group to use ATs. These conceptual heterogeneities may have resulted in statistical heterogeneity. There were no significant differences in TBUT, Schirmer's test score, fluorescein-staining score, or OSDI between CsA and ATs at baseline (online supplementary files 3 to 6 ).

\section{Primary Outcomes}

TBUT data for quantitative synthesis were available from six of the eleven trials..$^{25,28-30,34,36}$ Based on the data of 333 cases, CsA led to significantly higher TBUT scores than ATs (WMD 0.94, 95\% CI 0.08 $1.80)$ with high heterogeneity $\left(I^{2}=85 \%\right.$, Figure $\left.2 \mathrm{~A}\right)$. In subgroup analysis, however, significance was observed only for treatment duration $>3$ months (WMD 1.21, 95\% CI 0.36-2.05, online supplementary file 7) and comparison of CsA alone with ATs alone (WMD 1.74, 95\% CI 1.17-2.32). Interestingly, comparison of CsA alone and ATs alone showed a bigger effect size with reduced heterogeneity $\left(I^{2}=64 \%\right)$ than overall pooling (online supple mentary file 8 ). Results of meta-regression showed that mean age was not significantly associated with MD in TBUT scores between CsA and ATs and showed a positive trend (point estimate $0.03, P=0.58$, online supplementary file 9). To confirm the effect of CsA on TBUT score, we also applied sensitivity analysis, and the overall pooled trend was not significantly affected by any single trial (online supplementary file 10). No small-study bias (Egger's test, $t=-0.52, P=0.72$ ) was detected in the pooled result of TBUT (online supplemen tary file 11).

Five RCTs recruiting 269 cases with DED provided usable data on Schirmer's test scores, ${ }^{25,28,30,34,36}$ and pooled results showed no significant difference between the two groups, but a favorable trend for CsA over ATs (WMD $0.45,95 \%$ CI -2.25 to 3.15 ). Because this was a highly heterogeneous result $\left(I^{2}=86 \%\right.$, Figure $\left.2 \mathrm{~B}\right)$, we conducted further analyses. Then, we observed significant results at the first and second months, but an insignificant difference after the third month (online supplementary file 12). Moreover, we also found a better outcome from CsA in the anesthesia subgroup using Schirmer's test, but this result was based on only one trial. There were no significant differences between the two treatments using Schirmer's test II (online supplementary file 13). Interestingly, CsA alone showed a significantly better score on Schirmer's test than ATs alone (WMD 2.18, 95\% CI 1.62-2.74) with very low heterogeneity $\left(I^{2}=0\right)$. On the other hand, we observed no significance and very high heterogeneity for CsA plus ATs vs ATs alone ( $I^{2}=95 \%$, online supplementary file 14$)$. Furthermore, mean age was positively associated with MD in Schirmer's test score between CsA and ATs (point estimate 0.67, $P<0.001$, online supplementary file 15 ). There was noo evidence of small-study bias (Egger's test, $t=-1.57, P=0.38$ ) in the pooled results of Schirmer's test scores (online supplemen $\underline{\text { tary file } 16)}$.

\section{Secondary Outcomes}

Data for fluorescein staining were reported by only three RCTs (152 cases), ${ }^{28,30,36}$ and pooled results showed that CsA had significantly lower scores than ATs (standardized MD $-0.72,95 \%$ CI -1.28 to -0.16 ) with a relatively higher heterogeneity $\left(I^{2}=61 \%\right.$, Figure $\left.3 \mathrm{~A}\right)$. Appropriate OSDI-score data for quantitative synthesis were available from only two RCTs (102 DED cases).$^{30,34}$ Pooled results showed significantly lower OSDI scores for CsA than ATs (WMD $-4.75,95 \%$ CI -6.31 to -3.18 , Figure 3B) with very low heterogeneity $\left(I^{2}=0\right)$. Adverse-event data were 


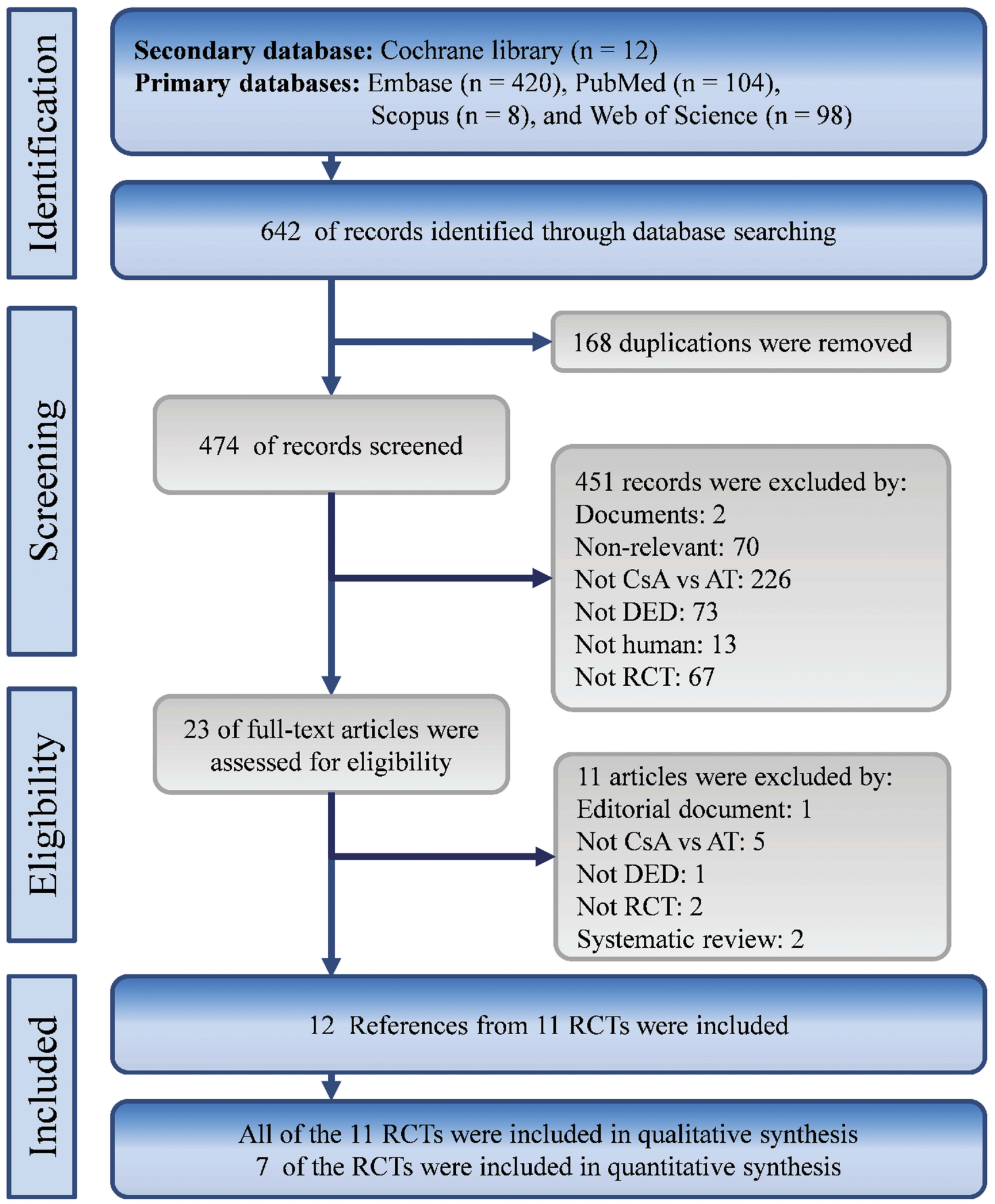

Figure I Flow diagram of evidence selection.

available from four trials (203 cases). ${ }^{25,27-29}$ Pooled adverse-event rate than ATs (Peto OR 7.70, 95\% CI results showed that CsA had a significantly lower 3.17-18.68) with low heterogeneity $\left(I^{2}=0\right.$, Figure $\left.3 \mathrm{C}\right)$. 
Table I Characteristics of included studies

\begin{tabular}{|c|c|c|c|c|c|c|c|c|c|}
\hline & \multirow[t]{2}{*}{ Location } & \multicolumn{2}{|c|}{$\begin{array}{l}\text { Sample Size } \\
\text { (Eyes) }\end{array}$} & \multirow{2}{*}{$\begin{array}{l}\text { Mean } \\
\text { Age, } \\
\text { Years }\end{array}$} & \multirow{2}{*}{$\begin{array}{l}\text { Sex } \\
\text { (Malel } \\
\text { Female) }\end{array}$} & \multirow[t]{2}{*}{ Blinding } & \multirow[t]{2}{*}{$\begin{array}{l}\text { Treatment } \\
\text { Group }\end{array}$} & \multirow[t]{2}{*}{$\begin{array}{l}\text { Treatment } \\
\text { Duration }\end{array}$} & \multirow{2}{*}{$\begin{array}{l}\text { Anesthesia } \\
\text { For Schirmer's } \\
\text { Test }\end{array}$} \\
\hline & & CsA & ATs & & & & & & \\
\hline IAltiparmak et al, $2009^{25}$ & Turkey & 25 & 48 & 41.6 & $6 / 31$ & NR & $\mathrm{Cs} \mathrm{A}+\mathrm{ATs}$ & 6 months & Yes \\
\hline Demiryay et al, $2011^{26}$ & Turkey & 44 & 40 & 45.50 & $2 / 40$ & Partially masked & $\mathrm{Cs} \mathrm{A}+\mathrm{ATs}$ & 4 months & No \\
\hline Kim et al, $2009^{27}$ & Korea & 100 & 100 & 39.45 & $40 / 60$ & Not masked & $\mathrm{Cs} \mathrm{A}+\mathrm{ATs}$ & 3 months & No \\
\hline Perry et al, $2006^{28}$ & USA & 32 & 34 & NR & NR & Double-masked & CsA alone & 3 months & Yes \\
\hline Prabhasawat et al, $2012^{29}$ & Thailand & 36 & 34 & 51.45 & $13 / 57$ & Double-masked & CsA alone & 3 months & No \\
\hline Rao et al, $2010^{30,31}$ & USA & 82 & 66 & 47.81 & $17 / 4 \mid$ & Investigator-masked & CsA alone & 12 months & Yes \\
\hline Salib et al, $2006^{32}$ & USA & 22 & 20 & 47 & $2 / 19$ & Double-masked & CsA alone & 4 months & Yes \\
\hline Schechter et al, $2009^{33}$ & USA & 42 & 32 & 73 & $24 / 13$ & Double-masked & CsA alone & 3 months & Yes \\
\hline Willen et al, $2008^{34}$ & USA & 44 & 44 & 43.1 & $7 / 37$ & Double-masked & CsA alone & 3 months & Yes \\
\hline Wu et al, $2009^{35}$ & China & 52 & 52 & 51 & $23 / 29$ & NR & $\mathrm{Cs} \mathrm{A}+\mathrm{AT} s$ & 3 months & No \\
\hline Yang et al, $2016^{36}$ & China & 68 & 68 & 51.33 & $30 / 72$ & NR & $\mathrm{Cs} A+\mathrm{ATs}$ & 2 months & No \\
\hline
\end{tabular}

Abbreviations: ATs, artificial tears; CsA, cyclosporin A; NR, not reported.

\section{Discussion Key Findings}

As we know, cytokine-driven and immunomediated inflammation will occur within the lacrimal functional unit, leading toward an alteration in tear quantity and composition. Our evidence confirmed the benefits of topical CsA drops on DED. The benefits were observed in not only subjective outcomes but also objective clinical parameters, including TBUT, fluorescence-staining tests and OSDI scores. These findings echo previous evidence of the weak association between subjective symptoms and objective parameters. ${ }^{37}$ Actually, it is important that CsA not only had benefits on objective parameters but also improved patients' subjective response. However, the benefits of CsA may be affected by treatment duration, combination therapy, and mean age at trial level.

Unfortunately, the data in this study cannot give a clear answer to the question of how treatment duration affects the effects of CsA on patients with DED. Our outcomes showed some inconsistent trends. For instance, TBUT showed that the effects of CsA became more evident with longer treatment duration ( $>3$ months). In contrast, Schirmer's test scores revealed that CsA had no more benefit for DED after a relatively longer period ( $>3$ months). These puzzling and uncertain results might have been due to a single-study effect and lack of data at the first- and second-month visits. Also, the mechanism of CsA on DED may have contributed to the inconsistency among outcomes. To clarify the effect of combination therapy of CsA and preservative-free ATs through subgroup analysis, interestinglycombination therapy did not have more benefit than ATs alone on either TBUT or Schirmer's test scores. These findings go against some previous studies. ${ }^{17,38,39}$ The mechanism of the interaction between CsA and ATs should be investigated in future.

Mean age at trial level may be another interesting factor affecting the efficacy of CsA. The current findings indicate that MDs in Schirmer's test scores between CsA and ATs were significantly associated with mean age. Although this phenomenon was not significant in the outcome of TBUT, a similar trend was observed. All these trends showed that topical CsA is probably more effective on DED in a relatively older population. A possible reason for these trends is that systemic use of Cs has a fast clearance rate in younger populations. Unfortunately, the current results only point to topical CsA yielding much better outcomes than ATs among relatively older patients with DED. We anticipate further study to investigate how age affects topical Cs pharmacokinetics among patients with DED.

\section{Comparing Recent Evidence And Argument}

Before our study, there had been several syntheses. In the last meta-analysis, CsA was compared to ATs, vehicle, or no topical treatment. The results were highly heterogeneous for OSDI, TBUT, Schirmer's test, and corneal fluorescein staining. Most studies have not declared the composition of their vehicles. The different formulation of the vehicle in each study may cause heterogeneity, though most patients with DED receive ATs in real- 


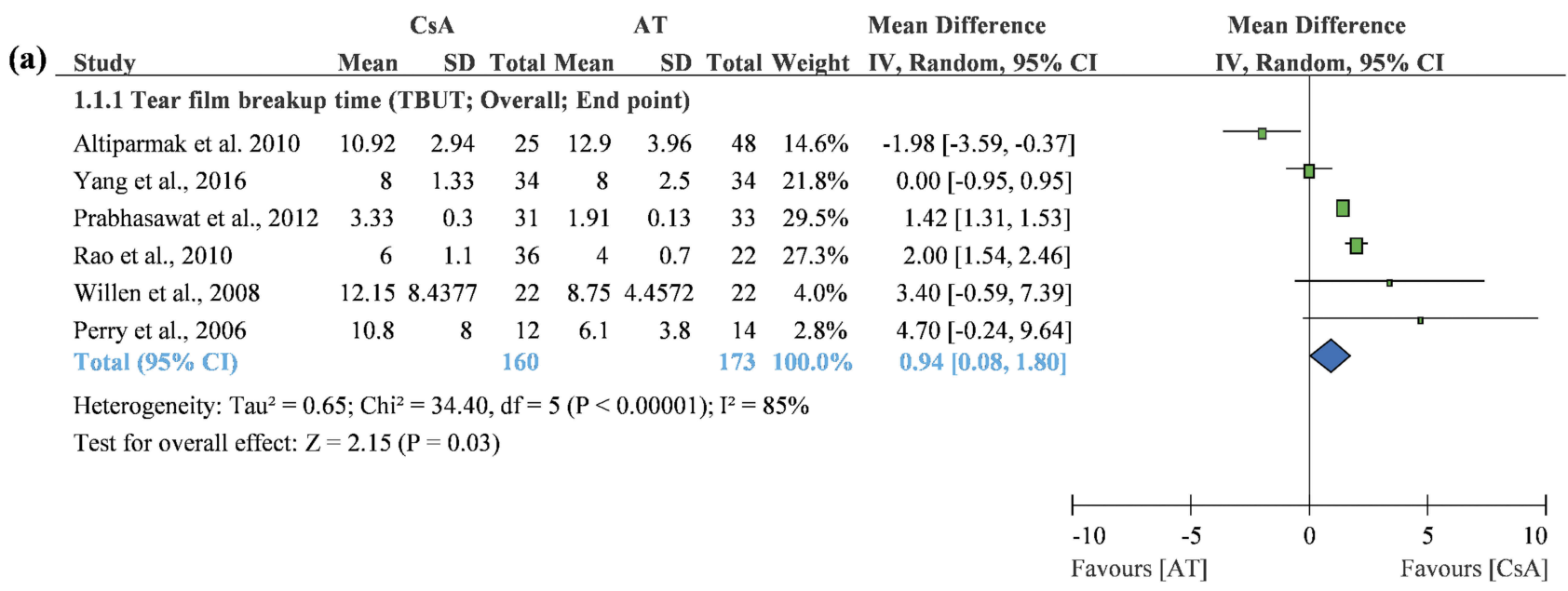

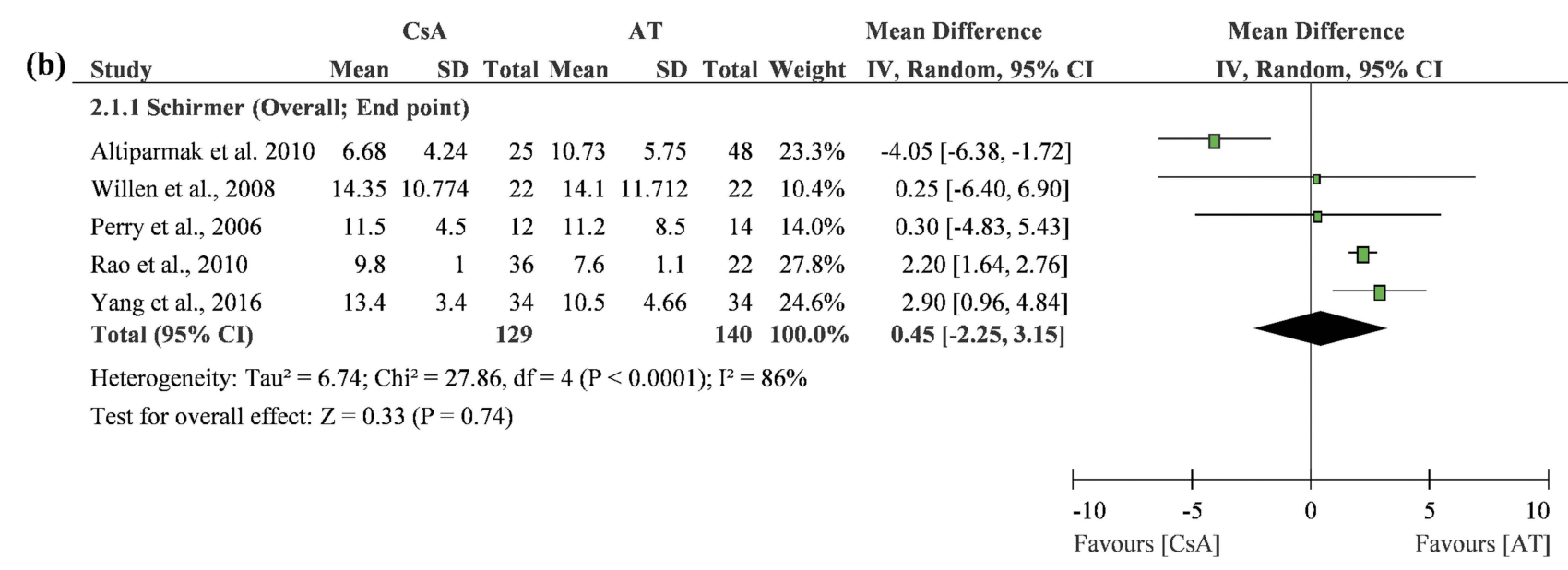

Figure 2 Forest plots of primary outcomes. (A) Tear film-breakup time. (B) Schirmer's test score.

world clinical practice. Therefore, to reflect real-world practice, our study focused only on those studies using ATs in a control group. We got pooled results with relatively lower heterogeneity than previous meta-analyses through subset analysis, and thus our results provide some insights for clinicians in clinical practice.

Our study also responds to a reflection on the effectiveness of CsA for DED through analyzing spending and prescriptions in the US. ${ }^{40}$ That article indicated that CsA was not effective for DED, but rather brought tears to eyes by burning billions in the US. Actually, the economic burden and controversial effect of CsA should be reconsidered in the real-world context and updated synthesized evidence, especially in this visual displayed era. ${ }^{41}$ In recent years, visual displayed terminal-related ocular symptoms have been increasing, and the prevalence of visual displayed-terminal DED (49.5\%) was higher than in the common population in recent year. ${ }^{42}$ Therefore, an appropriate interpretation for the increased spending on and prescriptions for CsA should be that spending on and prescriptions for CsA may be increased with the increasing prevalence of DED. Furthermore, a report indicated that definite DED leads to US\$799 work-productivity loss. ${ }^{43}$ It will be a huge loss when DED is not treated properly.

We agree with the criticism of insufficient evidence for the effectiveness of CsA in the previous systematic review by Schwartz and Woloshin. ${ }^{17,40}$ As such, we updated the synthesis with a meta-analysis for this issue. Our work provides direct evidence showing a better outcome for CsA than ATs in patients with DED, and the evidence overcame the criticism of single-group analysis by Schwartz and Woloshin. ${ }^{17,40}$ Although our study tried to provide stronger evidence through synthesizing trials with better study design and reducing conceptual heterogeneity from different comparators, evidence for different types of CsA needs to be discussed to gain better understanding on this topic. 


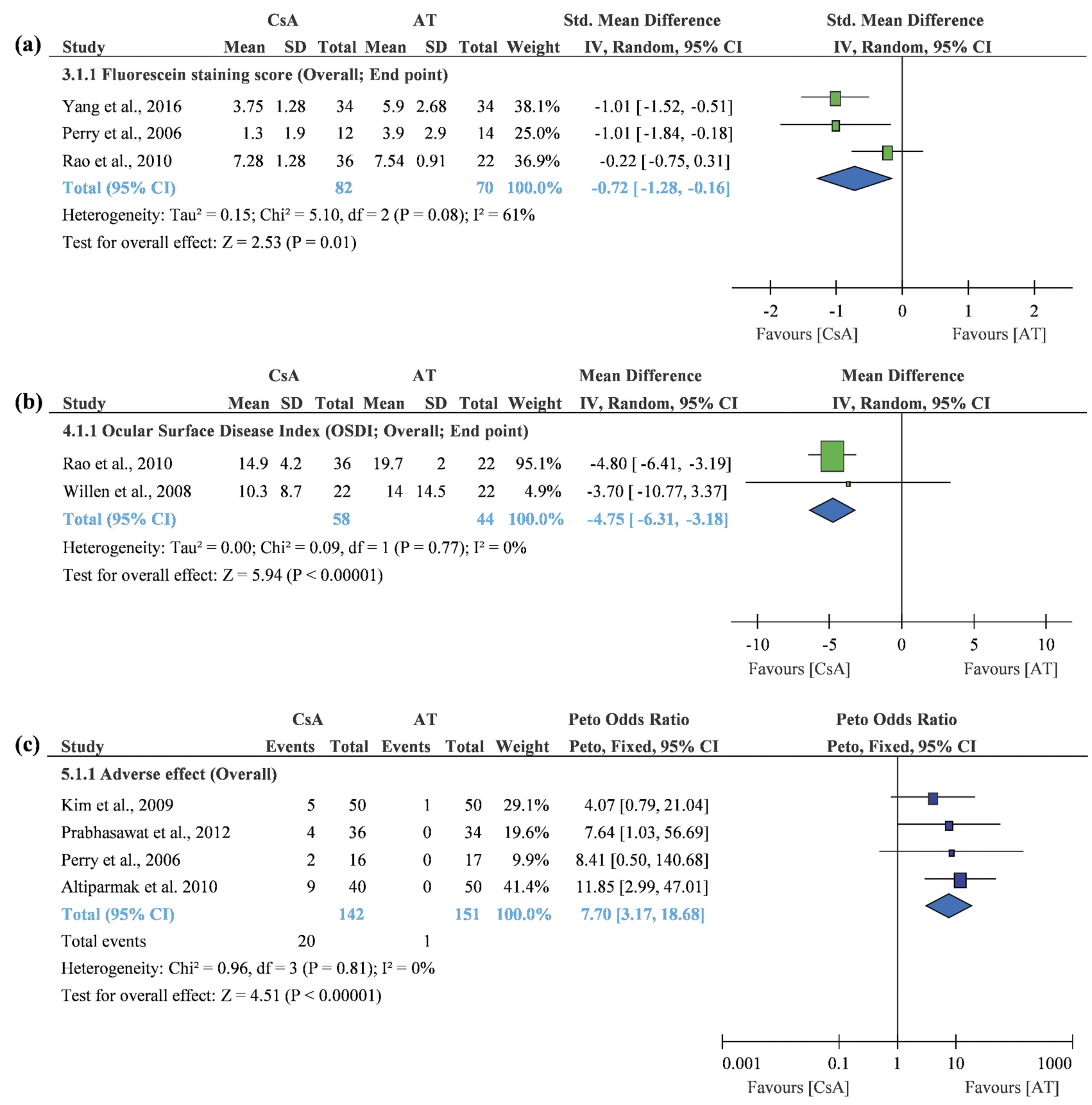

Figure 3 Forest plots of secondary outcomes. (A) Fluorescein-staining score. (B) Ocular surface disease-index score. (C) Adverse events.

For instance, an important type of CsA is worth taking into consideration, as we mentioned with regard to the effects of CsA on DED. Due to poor water solubility, the bioavailability and tolerability of typical oil-based CsA-delivery systems is an challenging issue. ${ }^{44}$ The novel cationic emulsion formulation was developed in the past decade, and several trials in Europe reported that CsA cationic emulsion was superior to vehicle in improving TBUT, Schirmer's test score, OSDI score, corneal fluorescein staining, and reduction in inflammatory markers. Though some ocular adverse effects were noted, systemic adverse events were not observed. ${ }^{8,45}$ As we mentioned before, we did not include these studies comparing CsA to vehicle because of the potential risk of causing heterogeneity. However, these trials using CsA with novel formulations provide further options in treating DED. Relevant information for the remarkable trials on this type of CsA was presented in Table 2.

As we know, it is important to treat patients with DED appropriately, because DED symptoms impair daily activities and workperformance. Increasing spending on and 
Table 2 Characteristics of pivotal studies of CsA CE

\begin{tabular}{|c|c|c|c|c|c|c|c|c|c|}
\hline & \multirow[t]{2}{*}{ Location } & \multicolumn{2}{|c|}{$\begin{array}{l}\text { Sample Size } \\
\text { (Eyes) }\end{array}$} & \multirow{2}{*}{$\begin{array}{l}\text { Mean } \\
\text { Age, } \\
\text { Years }\end{array}$} & \multirow{2}{*}{$\begin{array}{l}\text { Sex } \\
\text { (Malel } \\
\text { Female) }\end{array}$} & \multirow[t]{2}{*}{ Blinding } & \multirow[t]{2}{*}{$\begin{array}{l}\text { Treatment } \\
\text { Group }\end{array}$} & \multirow[t]{2}{*}{$\begin{array}{l}\text { Treatment } \\
\text { Duration }\end{array}$} & \multirow[t]{2}{*}{$\begin{array}{l}\text { Anesthesia For } \\
\text { Schirmer's Test }\end{array}$} \\
\hline & & CsA & Vehicle & & & & & & \\
\hline $\begin{array}{l}\text { Leonardi et al, } \\
2016^{45}\end{array}$ & Italy & 308 & 182 & 61.3 & $36 / 209$ & Double-masked & CsA alone & 6 months & No \\
\hline $\begin{array}{l}\text { Baudouin et al, } \\
2017^{8}\end{array}$ & France & 482 & 496 & 58.2 & $76 / 413$ & Double-masked & CsA alone & 6 months & No \\
\hline
\end{tabular}

Abbreviation: CsA, cyclosporin A.

prescription of CsA are a reality, but these trends cannot represent the failure of CsA. Although we agree that "standardised diagnostic criteria to assess the efficacy of topical CsA are recommended to improve the design of future RCTs in DED", ${ }^{17}$ we cannot deny that CsA may bring tears to DED patients' eyes.

\section{Limitations}

Though our study has many advantages, it also has some limitations. Firstly, we could not control for the influence from DED etiology, though we know that etiology might relate to disease progression. The RCTs included did not differentiate etiology, and our results might thus have been affected. Secondly, timing of interventions could not be well controlled. Because of various categorizations for timing of intervention in the RCTs, we cannot exclude this variation. Thirdly, the RCTs accommodated different DED severity, dosage, treatment frequency, and combinations (target treatment). Our study could not control for these potential factors contributing to heterogeneity, though we tried to reduce heterogeneity through excluding studies comparing CsA with vehicle. However, these limitations were not well controlled in previous systematic reviews either.

\section{Conclusion}

Overall, CsA is an effective option for treating patients with DED, yet our evidence showed attenuated treatment effects when CsA was combined with ATs. That result contradicts current clinical practice, and should be interpreted in clinical practice carefully. The combination effect of CsA with ATs needs to be clarified in future by three-arm RCTs. CsA may also be worth suggesting to relatively older patients with DED. Though the current evidence adds some new practical knowledge for clinicians in treating patients with DED, we still anticipate further RCTs to explore the effects of treatment duration, optimal dosage of CsA, and efficacy of CsA on different DED etiology.

\section{Abbreviations}

CsA, cyclosporin A; DED, dry-eye disease; WMD, weighted mean difference; OSDI, ocular surface-disease index; RCT, randomized clinical trial; TBUT, tear-breakup time.

\section{Author Contributions}

HIT systematically identified evidence, critically appraised the included articles, acquired data, managed data, and drafted the first version of the manuscript. SCC supervised the research and critically revised the manuscript. YNK designed the study, systematically identified evidence, analyzed the data, interpreted the results, and drafted the first version of the manuscript. All authors contributed to data analysis and drafting and revising the article, gave final approval of the version to be published, and agree to be accountable for all aspects of the work.

\section{Disclosure}

Dr Kang's current affiliations are at the Evidence-Based Medicine Center, Wan Fang Hospital, Taipei Medical University and Institute of Health Policy and Management, College of Public Health, National Taiwan University, Taiwan. The authors declare that they have nothing to disclose regarding funding or conflicts of interest with respect to this work.

\section{References}

1. Chia EM, Mitchell P, Rochtchina E, Lee AJ, Maroun R, Wang JJ. Prevalence and associations of dry eye syndrome in an older population: the Blue Mountains Eye Study. Clin Experiment Ophthalmol. 2003;31(3):229-232. doi:10.1046/j.1442-9071.2003.00634.x

2. Lin PY, Tsai SY, Cheng CY, Liu JH, Chou P, Hsu WM. Prevalence of dry eye among an elderly Chinese population in Taiwan: the Shihpai Eye Study. Ophthalmology. 2003;110(6):1096-1101. doi:10.1016/ S0161-6420(03)00262-8

3. McCarty CA, Bansal AK, Livingston PM, Stanislavsky YL, Taylor HR. The epidemiology of dry eye in Melbourne, Australia. Ophthalmology. 1998;105(6):1114-1119. doi:10.1016/S0161-6420(98)96016-X 
4. Farrand KF, Fridman M, Stillman IO, Schaumberg DA. Prevalence of diagnosed dry eye disease in the United States among adults aged 18 years and older. Am J Ophthalmol. 2017;182:90-98. doi:10.1016/j. ajo.2017.06.033

5. Schaumberg DA, Sullivan DA, Buring JE, Dana MR. Prevalence of dry eye syndrome among US women. Am J Ophthalmol. 2003;136 (2):318-326. doi:10.1016/s0002-9394(03)00218-6

6. Craig JP, Nichols KK, Akpek EK, et al. TFOS DEWS II definition and classification report. Ocul Surf. 2017;15(3):276-283. doi:10.1016/j.jtos.2017.05.008

7. Bron AJ, de Paiva CS, Chauhan SK, et al. TFOS DEWS II pathophysiology report. Ocul Surf. 2017;15(3):438-510. doi:10.1016/j. jtos.2017.05.011

8. Baudouin C, Figueiredo FC, Messmer EM, et al. A randomized study of the efficacy and safety of $0.1 \%$ cyclosporine A cationic emulsion in treatment of moderate to severe dry eye. Eur J Ophthalmol. 2017:27(5):520-530. doi:10.5301/EJO.5000952

9. Stern ME. Pathophysiology and allergy of the lacrimal functional unit: what goes wrong with our tear-secreting apparatus. Asian $J$ Ophthalmol. 2005;7(S1):5-8.

10. Jones L, Downie LE, Korb D, et al. TFOS DEWS II management and therapy report. Ocul Surf. 2017;15(3):575-628. doi:10.1016/j. jtos.2017.05.006

11. Marsh P, Pflugfelder SC. Topical nonpreserved methylprednisolone therapy for keratoconjunctivitis sicca in Sjogren syndrome. Ophthalmology. 1999;106(4):811-816. doi:10.1016/S0161-6420(99) 90171-9

12. Kunert KS, Tisdale AS, Stern ME, Smith JA, Gipson IK. Analysis of topical cyclosporine treatment of patients with dry eye syndrome: effect on conjunctival lymphocytes. Archiv Ophthalmol. 2000;118(11):1489-1496. doi:10.1001/archopht.118.11.1489

13. Turner K, Pflugfelder SC, Ji Z, Feuer WJ, Stern M, Reis BL. Interleukin6 levels in the conjunctival epithelium of patients with dry eye disease treated with cyclosporine ophthalmic emulsion. Cornea. 2000;19 (4):492-496. doi:10.1097/00003226-200007000-00018

14. Gao J, Sana R, Calder V, et al. Mitochondrial permeability transition pore in inflammatory apoptosis of human conjunctival epithelial cells and T cells: effect of cyclosporin A. Invest Ophthalmol Vis Sci. 2013;54(7):4717-4733. doi:10.1167/iovs.13-11681

15. Perry HD, Solomon R, Donnenfeld ED, et al. Evaluation of topical cyclosporine for the treatment of dry eye disease. Archiv Ophthalmol. 2008;126(8):1046-1050. doi:10.1001/archopht.126.8.1046

16. Alves M, Fonseca EC, Alves MF, et al. Dry eye disease treatment: a systematic review of published trials and a critical appraisal of therapeutic strategies. Ocul Surf. 2013;11(3):181-192. doi:10.1016/ j.jtos.2013.02.002

17. Sacchetti M, Mantelli F, Lambiase A, Mastropasqua A, Merlo D, Bonini S. Systematic review of randomised clinical trials on topical ciclosporin A for the treatment of dry eye disease. $\mathrm{Br} J$ Ophthalmol. 2014;98(8):1016-1022. doi:10.1136/bjophthalmol-201 3-304072

18. Wan KH, Chen LJ, Young AL. Efficacy and safety of topical $0.05 \%$ cyclosporine eye drops in the treatment of dry eye syndrome: a systematic review and meta-analysis. Ocul Surf. 2015;13(3):213225. doi:10.1016/j.jtos.2014.12.006

19. Zhou XQ, Wei RL. Topical cyclosporine A in the treatment of dry eye: a systematic review and meta-analysis. Cornea. 2014;33(7):760767. doi:10.1097/ICO.0000000000000123

20. Chang SH, Kang YN, Chiu HY, Chiu YH. A systematic review and meta-analysis comparing pigtail catheter and chest tube as the initial treatment for pneumothorax. Chest. 2018;153(5):1201-1212. doi:10.1016/j.chest.2018.01.048

21. Kao CC, Lin YS, Chu HC, Fang TC, Wu MS, Kang YN. Association of renal function and direct-acting antiviral agents for $\mathrm{HCV}$ : a network meta-analysis. J Clin Med. 2018;7(10). doi:10.3390/jcm7100314
22. Lin EY, Kuo YK, Kang YN. Effects of three common lumbar interbody fusion procedures for degenerative disc disease: a network meta-analysis of prospective studies. Int J Surg. 2018;60:224-230. doi:10.1016/j.ijsu.2018.11.009

23. Lin TM, Chi JE, Chang CC, Kang YN. Do etoricoxib and indometacin have similar effects and safety for gouty arthritis? A metaanalysis of randomized controlled trials. J Pain Res. 2019;12:8391. doi:10.2147/JPR.S186004

24. Moher D, Liberati A, Tetzlaff J, Altman DG. Preferred reporting items for systematic reviews and meta-analyses: the PRISMA statement. BMJ. 2009;339:b2535. doi:10.1136/bmj.b2651

25. Altiparmak UE, Acar DE, Ozer PA, et al. Topical cyclosporine A for the dry eye findings of thyroid orbitopathy patients. Eye. 2010;24 (6):1044-1050. doi:10.1038/eye.2009.246

26. Demiryay E, Yaylal V, Cetin EN, Yldrm C. Effects of topical cyclosporine A plus artificial tears versus artificial tears treatment on conjunctival goblet cell density in dysfunctional tear syndrome. Eye Contact Lens. 2011;37(5):312-315. doi:10.1097/ICL.0b013e318 22563be

27. Kim EC, Choi JS, Joo CK. A comparison of vitamin A and cyclosporine A $0.05 \%$ eye drops for treatment of dry eye syndrome. Am J Ophthalmol. 2009;147(2):206-213. doi:10.1016/j. ajo.2008.08.015

28. Perry HD, Doshi-Carnevale S, Donnenfeld ED, Solomon R, Biser SA, Bloom AH. Efficacy of commercially available topical cyclosporine A $0.05 \%$ in the treatment of meibomian gland dysfunction. Cornea. 2006;25(2):171-175. doi:10.1097/01. ico.0000176611.88579.0a

29. Prabhasawat P, Tesavibul N, Mahawong W. A randomized doublemasked study of $0.05 \%$ cyclosporine ophthalmic emulsion in the treatment of meibomian gland dysfunction. Cornea. 2012;31 (12):1386-1393. doi:10.1097/ICO.0b013e31823cc098

30. Rao SN. Topical cyclosporine $0.05 \%$ for the prevention of dry eye disease progression. J Ocul Pharmacol Ther. 2010;26(2):157-163. doi:10.1089/jop.2009.0091

31. Rao SN. Reversibility of dry eye deceleration after topical cyclosporine $0.05 \%$ withdrawal. J Ocul Pharmacol Ther. 2011;27(6):603609. doi:10.1089/jop.2011.0073

32. Salib GM, McDonald MB, Smolek M. Safety and efficacy of cyclosporine $0.05 \%$ drops versus unpreserved artificial tears in dry-eye patients having laser in situ keratomileusis. $J$ Cataract Refract Surg. 2006;32(5):772-778. doi:10.1016/j.jcrs.2005.10.034

33. Schechter BA, Katz RS, Friedman LS. Efficacy of topical cyclosporine for the treatment of ocular rosacea. Adv Ther. 2009;26(6):651659. doi:10.1007/s12325-009-0037-2

34. Willen CM, McGwin G, Liu B, Owsley C, Rosenstiel C. Efficacy of cyclosporine $0.05 \%$ ophthalmic emulsion in contact lens wearers with dry eyes. Eye Contact Lens-Sci Clin Pract. 2008;34(1):43-45. doi:10.1097/ICL.0b013e3180676d44

35. Wu AH, Wang BL, Pei S. Effect of cyclosporin A in the treatment of severe dry eye syndrome. Int J Ophthalmol. 2009;9(2):389-390.

36. Yang XB, Cao FZ. Clinical observation of cyclosporine eye drops with artificial tears for dry eyes. Int Eye Sci. 2016;16(5):923-926.

37. Sullivan BD, Crews LA, Messmer EM, et al. Correlations between commonly used objective signs and symptoms for the diagnosis of dry eye disease: clinical implications. Acta Ophthalmol (Copenh). 2014;92(2):161-166. doi:10.1111/aos.12012

38. Sall KN, Cohen SM, Christensen MT, Stein JM. An evaluation of the efficacy of a cyclosporine-based dry eye therapy when used with marketed artificial tears as supportive therapy in dry eye. Eye Contact Lens. 2006;32(1):21-26. doi:10.1097/01.icl.00001705 99.57728.29

39. Yavuz B, Bozdag Pehlivan S, Unlu N. An overview on dry eye treatment: approaches for cyclosporin a delivery. Scie World J. 2012;2012:194848. doi:10.1100/2012/194848 
40. Schwartz LM, Woloshin S. A clear-eyed view of restasis and chronic dry eye disease. JAMA Intern Med. 2018;178(2):181-182. doi:10.1001/jamainternmed.2017.7904

41. Parihar JKS, Jain VK, Chaturvedi P, Kaushik J, Jain G, Parihar AKS. Computer and visual display terminals (VDT) vision syndrome (CVDTS). Med J Armed Forces India. 2016;72(3):270-276. doi:10.1016/j.mjafi.20 16.03.016

42. Courtin R, Pereira B, Naughton G, et al. Prevalence of dry eye disease in visual display terminal workers: a systematic review and meta-analysis. BMJ Open. 2016;6(1):e009675. doi:10.1136/bmjopen-2015-009675
43. Yamada M, Mizuno Y, Shigeyasu C. Impact of dry eye on work productivity. Clinico Econ Outcomes Res. 2012;4:307-312. doi:10.2147/CEOR. S36352

44. Lallemand F, Felt-Baeyens O, Besseghir K, Behar-Cohen F, Gurny R. Cyclosporine A delivery to the eye: a pharmaceutical challenge. Eur J Pharm Biopharm. 2003;56(3):307-318.

45. Leonardi A, Van Setten G, Amrane M, et al. Efficacy and safety of $0.1 \%$ cyclosporine A cationic emulsion in the treatment of severe dry eye disease: a multicenter randomized trial. Eur J Ophthalmol. 2016;26(4):287-296. doi:10.5301/ejo.5000779

\section{Publish your work in this journal}

Drug Design, Development and Therapy is an international, peerreviewed open-access journal that spans the spectrum of drug design and development through to clinical applications. Clinical outcomes, patient safety, and programs for the development and effective, safe, and sustained use of medicines are a feature of the journal, which has also been accepted for indexing on PubMed Central. The manuscript management system is completely online and includes a very quick and fair peer-review system, which is all easy to use. Visit http://www. dovepress.com/testimonials.php to read real quotes from published authors. 